\title{
HISTÓRIA DO ESTUDO DA MIASTENIA GRAVE NA CLÍNICA NEUROLÓGICA DO HOSPITAL DAS CLÍNICAS DA FACULDADE DE MEDICINA DA UNIVERSIDADE DE SÃO PAULO
}

\author{
JOSÉ LAMARTINE DE ASSIS*
}

\begin{abstract}
RESUMO - É sintetizada a evolução histórica dos estudos sobre miastenia grave na Clínica Neurológica do Hospital das Clínicas da Faculdade de Medicina da Universidade de São Paulo no período 1950-1992. São relatados os principais resultados observados na terapêutica, na clínica e na fisiopatologia, sendo destacados os estudos imunológicos e os avanços em biologia molecular.
\end{abstract} molecular.

PALAVRAS-CHAVE: miastenia grave, timectomia, imunossupressão, plasmaférese, imunologia, biologia

History of the study of myasthenia gravis at Neurology Clinics of Hospital das Clínicas of the Faculty of Medicine of the University of São Paulo

SUMMARY - It is synthetized the evolution of the researches on myasthenia gravis at the Department of Neurology of the Hospital das Clínicas of the Faculty of Medicine, Medical School of the University of São Paulo (Brazil) between 1950 and 1992. The most important results observed about therapeutical, clinical and pathophysiological researches are reviewed. Immunologic studies and advances on molecular biology are emphasized.

KEY WORDS: myasthenia gravis, thymectomy, immunosuppression, plasmapheresis, immunology, molecular biology

As referências sobre miastenia gravis (MG) no Estado de São Paulo até a década de 40 são escassas. Até o final da década de 20, poucos trabalhos foram publicados sobre MG. Tratava-se de estudos essencialmente clínicos com alguma especulação de ordem fisiopatológica. A primeira referência sobre MG deve-se a Professor Enjolras Vampré, em comunicação feita na Sociedade de Medicina e Cirurgia de São Paulo, em 8-setembro-1915 $5^{51}$. Seguiram-se publicações de outros neurologistas paulistas, devendo ser lembradas as de Profs. Paulino W. Longo, Fernando de Oliveira Bastos e Adherbal Pinheiro Machado Tolosa, citados por Savoy ${ }^{43}$. Este autor defendeu a primeira tese sobre MG na CNHCFMUSP, em 1945. Tratava-se de estudo predominantemente clínico. Fatos de realce nesse estudo são a demonstração de fraqueza dos músculos respiratórios, mediante pneumogramas obtidos com o aparelho de Benedict-Roth, e a correção desse déficit pela prostigmina em pacientes clinicamente sem sintomas respiratórios.

A partir do início da década de 50 a MG foi estudada com interesse crescente na CNHCFMUSP, resultando na criação nessa Clínica, do primeiro grupo de estudos inicialmente voltado, para o tratamento da moléstia no país. Todas as facilidades para pesquisas clínica e laboratorial foram

Clínica Neurológica (CN), Hospital das Clínicas (HC), Faculdade de Medicina da Universidade de São Paulo (FMUSP): *Professor Associado, Departamento de Neurologia, FMUSP. Aceite: 27-janeiro-1994.

Dr. José Lamartine de Assis - Rua Votuporanga, 243 - 01256-000 São Paulo SP - Brasil. 
propiciadas pelo Chefe de Clínica na época, o saudoso Prof. Oswaldo Lange. A casuística em crescimento ininterrupto era, até o final de 1992, representada por 767 pacientes. Paralelamente ao aumento da casuística ocorreu evolução progressiva das pesquisas, que eram de ordem clínica com prevalência dos estudos com finalidade terapêutica. A partir do final da década de 60 os estudos foram orientados, também, ao campo da imunologia. Essa nova tendência das investigações na MG assumiu caráter universal e foi impulsionada nos anos 60 pela hipótese de doença auto-imune levantada por Simpson ${ }^{46}$ e outros autores ${ }^{32,35,36}$ no final da década de 50 e começo da década de 60 .

O assunto será desenvolvido a partir do início da década de 50 com Pesquisa Terapêutica e Estudos Clínicos. A seguir, são apresentados os Estudos Imunológicos, desenvolvidos a partir da década de 60 até o momento, culminando com os Estudos Neuro-Imune-Endocrinológicos na década de 80. Finalmente, serão mencionados Estudos Experimentais em Animais e Estudos sobre Biologia Molecular, iniciados no final da década de 80 e em prosseguimento nesta década; e Perspectivas Imediatas a Médio e Longo Prazos.

Pesquisa Terapêutica. Os primeiros estudos nesse campo visaram ao tratamento sintomático.

Tratamento Sintomático. Foram usadas na CNHCFMUSP as primeiras drogas anticolinesterásicas: neostigmina e brometo de piridostigmina, logo acrescidas com o cloreto de ambenônio após uso experimental com o nome de Mysuran ou Win $8077^{11}$. O cloreto de edrofônio desde o início foi usado como teste diagnóstico ${ }^{11}$. Naquela época foram estabelecidos na CNHCFMUSP os critérios gerais de administração e posologia dos anticolinesterásicos e seu emprego combinado (Tabela 1). Foram estudadas, também nessa primeira fase, numerosas drogas adjuvantes: efedrina, potássio, galantamina, inibidores da ovulação, guanidina, diacetato de germina e 4aminopiridina (4-AP) ${ }^{11}$.

Tratamento de Base Etiopatogênica. O tratamento conservador e o cirúrgico, isto é, a timectomia, foram iniciados na década de 50 na CNHCFMUSP e representaram a contribuição mais importante da Clínica nesse campo ${ }^{1,2,4,6-15}$. A timectomia precedeu o uso dos glicocorticóides. Estes foram iniciados em meados da década de 50 na CNHCFMUSP, de preferência em pacientes com formas severas (FS) de MG. A droga usada era o ACTH ou cortrofina e a via preferida era a intravenosa em gota a gota ${ }^{1,2}$. Os resultados foram surpreendentemente favoráveis na maioria das

Tabela 1. Anticolinesterásicos usados na CNHCFMUSP a partir do início da década de $50^{11}$.

Neostigmina* (Prostigmina)

Piridostigmina (Mestinon)

Cloreto de ambenônio (Mytelase)

Cloreto de edrofônio (Tensilon)

*Droga utilizada desde a década de 40 na CNHCFMUSP. vezes, numa época em que numerosos autores contra-indicavam seu uso em vista de piora por vezes alarmante. Na CNHCFMUSP essa piora ocorreu em $10 \%$ dos casos, o que não impediu que os glicocorticóides fossem mantidos como drogas de primeira escolha para as formas severas da doença $a^{1,2}$. Os resultados obtidos na CNHCFMUSP foram similares aos de outros centros de tratamento na época (período 1958-1978) (111,12 $^{8}$ (Tabelas 2 e 3).

Tabela 2. Glicocorticóides na MG: período 1958-1978. Resultados[1,2,12].

\begin{tabular}{lccccc}
\hline Hormônio & Casos & MI & NI & MI (\%) & NI (\%) \\
\hline \hline ACTH & 28 & 21 & 7 & 75 & 25 \\
Corticóide & 42 & 34 & 8 & 81 & 19 \\
Total & 70 & 55 & 15 & 78,6 & 21,4 \\
\hline
\end{tabular}

MI, remissão completa ou melhora importante; NI, não influenciado ou pouco melhorado. 
Tabela 3. Tratamento da $M G$ : resultados da prednisona[1,2,12].

\begin{tabular}{lcc}
\hline \multicolumn{1}{c}{ Autor } & $\mathrm{N}^{\circ}$ & $\mathrm{RC} \mathrm{ou} \mathrm{MI} \mathrm{( \% )}$ \\
\hline \hline Oosterhuis & 52 & 73,1 \\
Sanders & 50 & 91,7 \\
Sghirlanzoni & 60 & 71,6 \\
Assis & 42 & 81,0 \\
\hline
\end{tabular}

$\mathrm{N}^{\circ}$, pacientes tratados durante a década de 1970 ;

RC remissão completa; MI, melhora importante.

Paralelamente aos estudos no campo do tratamento conservador da MG, na CNHCFMUSP foram estabelecidos critérios para o tratamento cirúrgico, inclusive para os pacientes timomatosos. Na primeira fase da evolução desses estudos, a indicação da timectomia para os não timomatosos obedecia os mesmos critérios adotados por Eaton e Clagett ${ }^{17}$ e Simpson ${ }^{45}$, isto é, eram seletivamente timectomizados jovens do sexo feminino e com menos de 5 anos de doença. Essa conduta limitou muito o número de timectomizados na década de 50 até meados da década de 60 na CNHCFMUSP. Com a tendência
as restrições quanto à idade, sexo e duração da ulterior de indicação cada vez mais ampla e sem as restrições quanto à idade, sexo e duração da
doença, o número de timectomizados aumentou significativamente na CNHCFMUSP. Em 1978 foram publicados os primeiros estudos com avaliação dos resultados dos pacientes operados no período 1958-1978 na CNHCFMUSP ${ }^{6,11,12}$. Esses resultados foram superponíveis aos apresentados por outros autores no período (Tabela 4).

A partir da década de 70 o uso rotineiro e intensivo da prednisona pela via oral, acrescido do preparo dos pacientes com corticóide para timectomia, acarretou não só ampliação da indicação da cirurgia como melhora significativa de seus resultados na CNHCFMUSP ${ }^{12}$. Após estudo comparativo de pacientes com e sem preparo pela prednisona ${ }^{7}$, o método com preparo tornou-se rotineiro na CNHCFMUSP, porém com indicação baseada em critérios bem estabelecidos para cada caso ${ }^{7,11,12}$. No período 1972-1987 o número de pacientes timectomizados com preparo ascendia a 59 (Tabela 5) o que, acrescido dos pacientes operados sem preparo a partir da década de 50 , levou esse número a atingir o total de 282 no período $1958-1990$ (Tabela 6).

A timectomia ainda foi estudada quanto à indicação e resultados em crianças $^{14} \mathrm{e}$ idosos ${ }^{15}$, tendo sido estabelecidos critérios para indicação nesses grupos etários. Por último, recentemente, foram avaliados os resultados em pacientes acompanhados por períodos de 8 a 25 anos da timectomia versus tratamento conservador, apesar das enormes dificuldades que um estudo dessa natureza acarretou $^{10,12}$.

Tabela 4. Miastenia grave: timectomia via transesternal. Periodo 1958-1978. Resultados (\%) [6,11,12].

\begin{tabular}{lccccc}
\hline & & \multicolumn{2}{c}{ Número } & \multicolumn{2}{c}{ RC ou MI (\%) } \\
\cline { 3 - 6 } Autor & Data & Timom. & Não timom. & Timom. & Não timom. \\
\hline \hline Simpson & 1958 & 36 & 258 & 11 & 34 \\
Oosterhuis & 1964 & 10 & 13 & 30 & 53 \\
Perlo e col. & 1966 & 88 & 188 & $35^{* *}$ & $89 *$ \\
Mulder e col. & 1972 & 17 & 50 & 44 & 80 \\
Slater e col. & 1978 & 141 & - & 7 & - \\
Assis e Curi & 1978 & 9 & 64 & $44^{* * *}$ & 80 \\
\hline
\end{tabular}

* Pacientes do sexo feminino e menos de $2 \%$ dos óbitos; ** pacientes de ambos os sexos com timoma e $65 \%$ de óbitos; ${ }^{* * *}$ pacientes timomatosos com predomínio do sexo masculino e $56 \%$ de óbitos. Timom, timomatoso. 
Tabela 5. Tratamento da MG: timectomia e prednisona. Período 1972-1987* [7,11,12].

\begin{tabular}{lccc}
\hline \multicolumn{1}{c}{ Métodos } & Pacientes $\left(\mathrm{n}^{\circ}\right)$ & $\%$ & MI ou RC (\%) \\
\hline \hline Preparo com prednisona & 59 & 62,1 & 80 \\
Prednisona após timectomia & 36 & 37,9 & - \\
Total & 95 & 100 & 80 \\
\hline
\end{tabular}

* Primeiro semestre; MI, melhora importante; RC, remissão completa.

Tabela 6. Timectomia na miastenia grave em 282 pacientes: idade e duração da doença[13].

\begin{tabular}{cccccc}
\hline Idade (anos) & $\mathrm{N}^{\circ}$ pacientes & $\%$ & Duração da doença & $\mathrm{N}^{\circ}$ pacientes & $\%$ \\
\hline $0-10$ & 7 & 2,5 & $15-20 \mathrm{~d}$ & 4 & 1,4 \\
$11-15$ & 27 & 9,5 & $15 \mathrm{~d}-1 \mathrm{a}$ & 94 & 33,3 \\
$16-30$ & 159 & 56,3 & $1-2 \mathrm{a}$ & 82 & 29,0 \\
$31-50$ & 65 & 23,0 & $15 \mathrm{~d}-2 \mathrm{a}$ & 153 & 54,6 \\
$>50$ & 19 & 7,0 & $25 \mathrm{~m}-10 \mathrm{a}$ & 95 & 33,6 \\
& & & $15 \mathrm{~d}-10 \mathrm{a}$ & 248 & 88,0 \\
SR & 5 & 1,7 & não determinado & 17 & 6,0 \\
\hline
\end{tabular}

a, anos; d, dias; m, meses; SR, sem referência.

A partir de 1980 foram estudadas na CNHCFMUSP terapias novas de base etiopatogênica, devendo ser destacados a plasmaférese e o emprego das drogas citolíticas para imunossupressão medicamentosa não esteróide ${ }^{9}$.

A plasmaférese foi executada pela primeira vez na CNHCFMUSP em 1980, mediante procedimento manual em uma paciente com crise miastênica $(\mathrm{CM})$ refratária a todos os tratamentos ${ }^{22}$. A partir da introdução dos processadores celulares (método automático), o método tornou-se rotineiro na CNHCFMUSP. Assim como nos outros procedimentos terapêuticos recém-introduzidos na CNHCFMUSP, foram estabelecidos critérios adequados para a indicação da plasmaférese após a fase inicial, quando ocorreu algum exagero com base em previsões muito otimistas sobre o método ${ }^{55}$.

A imunossupressão medicamentosa não esteróide realizada com as drogas citolíticas, empregada em raros pacientes (de regra timomatosos) nas décadas de 50 e 60 , passou a ser usada em rotina, embora em menor número de miastênicos, timomatosos ou não e que respondiam pobremente aos demais tratamentos ${ }^{9,30 a}$. O número de pacientes assim tratados vem crescendo nos últimos anos,

Tabela 7. Citostáticos usados na CNHCFMUSP ${ }^{9,30 a}$.
Azatioprina
Clorambucil
Ciclofosfamida
Metotrexate

chegando a 57 em 1992. As drogas usadas até o momento são vistas na Tabela 7 e o número de pacientes tratados e respectivas drogas são vistos na Figura 1.

Outros métodos de tratamento de base etiopatogênica também foram estudados: radioterapia mediastinal; irradiação do corpo todo; ciclosporina A, esplenectomia. A radioterapia 


\section{Miastenia grave Citolíticos}

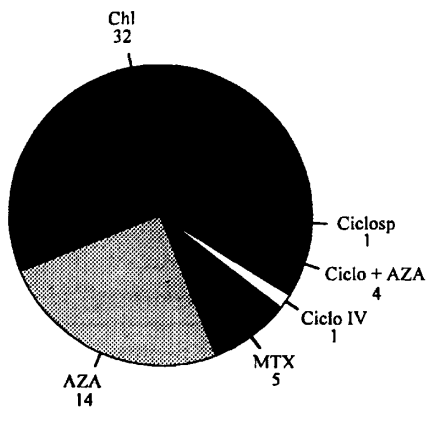

Fig 1. Miastenia grave. Citolíticos (57 pacientes). Chl, clorambucil; AZA, azatioprina; Ciclo, ciclofosfamida; Ciclo IV, ciclofosfamida intravenosa; MTX, metotrexate. mediastinal começou a ser empregada na década de 50 e início da década de 60 em pacientes timomatosos ou não, que respondiam pobremente aos tratamentos clássicos ${ }^{11}$. A irradiação de corpo inteiro é de emprego mais recente na CNHCFMUSP e indicada em pacientes refratários a todos os tratamentos, o mesmo ocorrendo com a ciclosporina $\mathrm{A}^{27,54}$. A esplenectomia, proposta com base em aspectos imunopatogênicos da MG, não foi realizada na CNHCFMUSP, pois um paciente dessa série desenvolveu MG generalizada 5 anos após ter sido esplenectomizado por rotura traumática do baço. Esse fato reforçou a impressão de que a base fisiopatogênica do método não era convincente ${ }^{18 a}$.

Estudo das Crises Miastênica (CM) e Colinérgica (CC). No período de 1953-1963 as CM e CC constituíram sério problema terapêutico na CNHCFMUSP. Os índices de morbidade $\mathrm{e}$ mortalidade eram muito elevados. Com a modernização das UTIs e o emprego rotineiro do método do "repouso da placa" a partir de meados da década de 60 na CNHCFMUSP, aqueles índices caíram significativamente. $O$ "repouso da placa" foi iniciado no final da década de 50 , a partir da curiosa observação de um paciente com quadro bulbar e insuficiência respiratória grave internado na enfermaria de paralisia infantil do Instituto de Ortopedia do HCFMUSP. A respiração assistida foi acompanhada, após 72 horas, de recuperação total do paciente que, na realidade, era miastênico e não poliomielítico ${ }^{4}$.

O estudo do "repouso da placa" a partir desse caso permitiu a utilização do método em todos os miastênicos com CM ou CC na CNHCFMUSP. No final da década de 60, na CNHCFMUSP, o "repouso da placa" nos casos de CM ou CC resistentes foi acrescido de prednisona pela via oral. A partir da década de 80 o método, associado ou não a prednisona, passou a contar com a plasmaférese no tratamento dessas crises.

Estudos Clínicos da MG. Embora os estudos sobre terapêutica da MG fossem predominantes desde a década de 50 na CNHCFMUSP, os aspectos clínicos da doença não foram negligenciados. Nesse particular prevaleceram os estudos clínico-laboratoriais desenvolvidos principalmente nas décadas de 70 e 80 , e assim mantidos até o presente momento. Foram estudados a MG associada $^{11,15 b, 18 h, 49}$, a eletrovetocardiografia ${ }^{11}$, eletrofisiologia e eletroneuromiografia ${ }^{21}$, radiologia contrastada do timo ${ }^{3}, \mathrm{MG}$ na gravidez, parto, puerpério e ciclo menstrual ${ }^{11} \mathrm{e}$, mais recentemente, foi salientada atrofia da língua em geral desenvolvida em pacientes com forma severa e disfonia persistente desde o início ${ }^{15}$. Na década de 80 a tomografia computadorizada do tórax (TAC) tornou-se de emprego rotineiro na CNHCFMUSP para visualização da região tímica ${ }^{48}$.

Ainda nessa década foi realizado estudo das correlações imune-histológico-topográficas, isto é, investigação topológica (TAC) e estudo histológico do timo e, paralelamente, determinação de anticorpos no soro sanguíneo contra o AChR (anti-AChR) ${ }^{23,24,39}$ e contra músculo estriado humano (AEMA) $)^{26,37,52,53}$.

A histologia do timo vem sendo estudada desde que se iniciou o tratamento da MG pela timectomia na CNHCFMUSP, o que aconteceu no começo da década de 50. Graças a esses estudos foi possível avaliar aspectos da patologia tímica $(80 \%$ dos pacientes apresentam hiperplasia tímica, $10 \%$ timomas e o restante atrofia e timo normal $)^{11,56}$, fatores demográficos e alterações clínicas e 
histologicas resultantes da administração prévia da prednisona ${ }^{56 a}$ e correlações clínicas e histopatológicas ${ }^{306,56}$.

O emprego da coloração pelo picrosyrius e microscopia eletrônica de músculos intercostais de miastênicos mostrou, na década de 80 , modificações em poliribossomas e mitocôndrias, sugerindo alterações inespecíficas. Esses achados são importantes porque alguns desses pacientes tinham 0 diagnóstico de miastenia ocular pura ${ }^{11,12}$.

Nos estudos clínicos devem ser destacados os exames auxiliares.

Exames Auxiliares no Diagnóstico da MG. Iniciados na década de 50 e que culminaram na década de 80 com a determinação do anti- $\mathrm{AChR}^{23,24}$, anticorpo contra antígeno extraível de músculo de coelho (EMA) e de músculo humano (AEMA) ${ }^{26,52,53}$ e com a realização dos testes pulmonares $^{11,30,41,42}$. Nas décadas de 50 e 60 foram estudados métodos para avaliação das timopatias, em particular a pneumomediastinografia ${ }^{3,11} \mathrm{e}$ a venografia tímica ${ }^{11}$. Esses métodos foram abandonados com o advento da TAC ${ }^{48}$. De maior importância para o diagnóstico clínico e de timomas foi a determinação dos anticorpos no soro de pacientes com MG na CNHCFMUSP e que estão resumidos no item Estudos Imunológicos no Campo Humoral. Outro método diagnóstico da MG se baseia na avaliação das provas respiratórias e vem sendo estudado na CNHCFMUSP desde a década de 70.0 método se baseia nas modificações da curva fluxo-volume similares àquelas observadas nas estenoses da traquéia: a curva aparece achatada, tanto na inspiração como na expiração, desenhando mais uma figura retangular que a losângica encontrada nos normais. Esse aspecto caracteriza o que se convencionou chamar de "padrão miastênico"; esse padrão é encontrado em cerca de $90 \%$ dos miastênicos, em todas as suas formas clínicas. Trata-se de método original e de real valor diagnóstico ${ }^{30 c, 41,42}$.

Estudos Imunológicos na MG. Na CNHCFMUSP esses estudos foram iniciados na década de 60, antes que o AChR fosse definitivamente implicado na patogênese da MG. Inicialmente, as investigações focalizaram a determinação do anticorpo antimúsculo estriado (AcAM) no soro de pacientes com MG. Os resultados obtidos na CNHCFMUSP foram comparáveis aos de outros autores

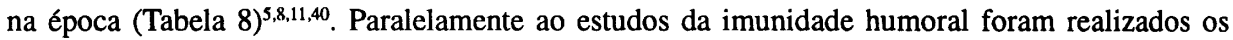
primeiros estudos sobre imunidade celular na CNHCFMUSP ${ }^{33}$. A partir da década de 80 os estudos imunológicos da MG experimentaram importante incremento na CNHCFMUSP, graças ao crescimento mais rápido da casuística e, principalmente, à somação de esforços, capacitação e interesse de nova geração de biólogos, técnicos de laboratório e pessoal médico, tendo à frente Paulo Eurípedes Marchiori. Os resultados desses estudos foram publicados em revistas nacionais e estrangeiras e/ou apresentados em congressos e jornadas no país e no exterior ${ }^{8,16,20,23,28,29,30 c, 31,37-39,50 a, 52,53}$ e em teses na FMUSP ${ }^{24,26,50}$.

Estudos Imunológicos no Campo Humoral. As principais pesquisas imunológicas humorais na CNHCFMUSP foram realizadas a partir de 1983 e culminaram com a determinação do anti-

Tabela 8. Anticorpo antimúsculo na MG adquirida. Testes de imunofluorescência [5,8,11,40].

\begin{tabular}{ccccc}
\hline Autor & Ano & Resposta & Números & AcAM (\%) \\
\hline \hline Simpson & 1966 & + & 1 & 10 \\
& & total & 10 & \\
Van Der Geld e & 1964 & + & 38 & 38,7 \\
col. & & total & 98 & \\
Assis e Saraiva & 1971 & + & 18 & 33,3 \\
\hline
\end{tabular}

+ , positivo; AcAM, anticorpo antimúsculo esquelético. 
$\mathrm{AchR}^{23,24}$, EMA e $\mathrm{AEMA}^{26,52,53}$. O anti-AchR foi determinado mediante radioimunoensaio e foi totalmente otimizado em nosso meio ${ }^{23,24}$. As dificuldades operacionais foram e continuam imensas. De 1983 a 1991 foram realizadas cerca de 1200 determinações séricas. Inúmeros foram os substratos antigênicos de diferentes espécies animais utilizados. Esporadicamente foram também determinados anticorpos bloqueadores ${ }^{24}$. A dosagem do anti-AchR foi conseguida mais recentemente mediante precipitações com IgG anti-humana em lugar do polietilenoglicol como havia sido utilizado até então $0^{24}$. Os AcAM, inicialmente, foram determinados por imunofluorescência ${ }^{5,40} \mathrm{e}$, a seguir, por hemaglutinação usando-se antígeno de músculo heterólogo de coelho ${ }^{37}$. Dada a inespecificidade do método (30\% de MG não timomatosa foram positivos), passou-se a usar a técnica do ELISA ${ }^{52,53} \mathrm{com}$ antígenos de músculo humano, o que acarretou elevada positividade na MG timomatosa ${ }^{26}$. A determinação desses anticorpos séricos na MG representou o resultado mais importante dos estudos no campo imunológico dessa doença na década de 80, na CNHCFMUSP. Imunecomplexos ${ }^{25}$, imuneglobulinas séricas e outros anticorpos foram determinados e relacionados a formas clínicas da $\mathrm{MG}^{20,38}$.

Estudos Imunológicos no Campo Celular. Em 1985 os estudos de subpopulações de linfócitos circulantes revelaram modificações nos linfócitos B (Fab'2) e no agrupamento de linfócitos T totais $\left(\mathrm{T}_{3}\right)$ determinado pela técnica de roseta com hemácias de carneiro, enquanto as frações $\mathrm{T}_{4}, \mathrm{~T}_{8} \mathrm{e}$ células imaturas (dupla marcação) não se modificaram nem mesmo nos pacientes previamente timectomizados.

Com o advento dos anticorpos monoclonais que abriu amplas perspectivas para investigações imunológicas e terapêuticas, novos estudos estão sendo realizados na CNHCFMUSP, com ampliação do espectro desses anticorpos e, portanto, das subpopulações linfocitárias presentes no sangue periférico e no timo. Em estudos recentes foi verificada redução das subpopulações $T_{4}, T_{3}, T_{8}$, aumento de CD5 e células imaturas, CD-CD8; esse achado mostra o caráter dismaturacional das subpopulações linfocitárias do timo. Tem sido aventada, ainda, a possibilidade de se avaliar modificações no gene da apoptose do timo. Estão em andamento extrações da RNA e DNA do timo para estudo posterior de receptor específico de linfócito $T$ (TCR).

Outro campo que está sendo investigado é o dos receptores. Foi realizado estudo de receptores de membrana sendo determinados os receptores de glicocorticóides (RGC), em leucócitos mononucleares do sangue periférico de pacientes com $\mathrm{MG}^{16}$. Estão sendo estudadas a padronização de repectores de timos normais, a determinação de RGC, andrógenos e estrógenos em timos e linfócitos, análise fenotípica de linfócitos tímicos de pacientes com $\mathrm{MG}^{28}$. O estudo desses receptores hormonais em linfócitos e no timo reforça o envolvimento neuro-imune-endócrino na etiopatogenia da $\mathrm{MG}^{11}$.

Imunogenética. Em meados da década de 80 foi realizada a tipagem do antígeno HLA classe I em 65 pacientes com MG, sendo adotado grupo controle de 447 indivíduos considerados normais. Usou-se a técnica da microlinfotoxicidade (NIH). Houve predomínio significante do alelo $\mathrm{B}_{8}{ }^{30}$.

Estudos Neuro-Imune-Endocrinológicos. O caráter auto-imune da MG envolve disfunção do sistema neuro-imunendócrino (SNIE). Os estudos nesse campo na CNHCFMUSP foram iniciados na década de 80, tendo sido estudado o eixo hipotálamo-pituitário-gonadal (HPG) de 33 pacientes com MG. Foram avaliados receptores esteróides em timos, receptores de glicocorticóides em linfócitos periféricos e em timos. O eixo HPG foi analisado mediante determinação dos níveis hormonais séricos. Fato relevante nesse estudo é que o receptor esteróide no timo e nos linfócitos de pacientes com MG mostrou envolvimento do SNIE na patogenia da doença $\mathrm{a}^{30 \mathrm{~d}}$.

Modelo Experimental. No final da década de 80 e início da atual década foi desenvolvido com sucesso modelo experimental de MG (MGAE) em ratos Wistar, Low M e Lewis, mediante a administração de um pool de imunoglobulinas provenientes de pacientes com MG. Níveis elevados de anti-AchR foram acompanhados de manifestações clínicas severas e morte dos animais ${ }^{50,50 a}$. 
Preparação Nervo-Músculo. Em preparação neuromuscular de rato (Wistar, Low M) e camundongo (Balb/C), foi avaliada a contração do músculo e o efeito bloqueante do anti-AChR (IgG-anti-AChR de pacientes miastênicos). Os achados clínicos e eletrofisiológicos na preparação foram proporcionais aos níveis de anti-AChR ${ }^{30 c}$.

Estudos sobre Biologia Molecular na MG. Em face do avanço da medicina no campo da Biologia Molecular, recentemente foram iniciados na CNHCFMUSP estudos nesse campo relacionados à MG. Foram determinados os pesos moleculares e identificadas 6 frações antigênicas no músculo responsáveis pelo estímulo à produção de AcAM. A partir do final da década de 80 foram determinados RNA e DNA no timo. Atualmente estão sendo extraídos RNA e DNA de timos miastênicos para estudos do receptor de linfócitos T-TCR específico por sondas. Com a intenção de se avaliar a gênese das modificações tímicas na MG, estão sendo desenvolvidos, atualmente, estudos sobre os receptores de integrinas-VLAS, fibronectina, laminina e de outras moléculas de adesão, em linfócitos de timo miastênico. Os resultados preliminares já estão aparecendo ${ }^{29}$.

Perspectivas Imediatas. A produção de globulinas anti-timocitárias purificadas, a nível comercial, pelo Laboratório de Transplantes e Imunogenética do INCOR-HCFMUSP permitirá a avaliação de seu emprego no tratamento de pacientes com MG resistentes à terapêutica habitual.

Perspectivas a Médio e Longo Prazos. Desenvolvimento de anticorpos monoclonais no tratamento da MG e outras doenças auto-imunes.

\section{REFERÊNCIAS}

1. Assis JL. Tratamento dos casos graves de miastenia: ação do ACTH e cortisona. Considerações a propósito de três casos. Arq Neuropsiquiatr 1956, 14: 28-36.

2. Assis JL. Tratamento das formas severas de miastenia pelo ACTH por via intravenosa. Arq Neuropsiquiatr 1960, 18: 359-382.

3. Assis JL, Carvalho L. Radiologia contrastada do timo na miastenia grave. Arq Neuropsiquiatr 1964, 22: 33-43. 4. Assis JL, Saraiva PAP. Repouso da junção neuromuscular no tratamento das crises miastênicas e colinérgicas. Arq Neuropsiquiatr 1968, 26: 93-104.

5. Assis JL, Saraiva S. Myasthenia gravis: therapeutical immunological correlation. Rev Hosp Clín Fac Med S Paulo 1971, 26: 213-216.

6. Assis JL, Curi N. Timectomia na miastenia grave: avaliação dos resultados em 78 pacientes. Arq Neuropsiquiatr 1978, 36: 16-26.

7. Assis JL, Marchiori PE, Zambon AA, Filomeno LTE, Scaff M. Immunosuppression with corticosteroids and thymectomy in myasthenia gravis: an evaluation of immediate and short term results in 20 patients. Arq Neuropsiquiatr 1985, 43: 17-21.

8. Assis JL. Miastenia grave: evolução das pesquisas na Clínica Neurológica do Hospital das Clínicas da Faculdade de Medicina da USP. Arq Neuropsiquiat 1986, 44: 406-414.

9. Assis JL, Marchiori PE, Scaff M, Zambon AA. Tratamento da miastenia grave mediante imunossupressão medicamentosa não esteróide. Arq Neuropsiquiatr 1986, 44: 109-116.

10. Assis JL, Marchiori PE, Zambon AA, Scaff M. Tratamento conservador e timectomia na miastenia grave: resultados observados em dois grupos de pacientes acompanhados a longo prazo. Arq Neuropsiquiat 1987, 45: 119-130.

11. Assis JL. Miastenia grave. São Paulo: Sarvier, 1990.

12. Assis JL. Miastenia grave: avaliação crítica dos tratamentos. Arq Neuropsiquiatr 1990, 48: 55-70.

13. Assis JL, Marchiori PE, Zambon AA, Scaff M. Thymectomy for myasthenia gravis: evaluation of results in 282 patients. Rev Hosp Clín Fac Med S Paulo 1992, 47: 117-120.

14. Assis JL, Marchiori PE, Zambon AA, Scaff M. Juvenile myasthenia gravis and thymectomy: report of ten cases. Rev Hosp Clín Fac Med S Paulo 1992, 47: 234-236.

15. Assis JL, Marchiori PE., Zambon AA, Scaff M. Thymectomy in over 50 years-old patients with myasthenia gravis: long and short-term results in 21 patients. Rev Hosp Clin Fac Med S Paulo 1993, 48: 22-24.

15a. Assis JL, Marchiori PE., Zambon AA, Scaff M. Atrophy of the tongue in myasthenia gravis: report of 8 patients. In Congreso Panamericano de Neurologia 8. Montevideo, 1991, p 131.

15b. Baeta AM, Haddad MS, Tinone G, Assis JL, Marchiori PE, Scaff M. Myasthenia gravis associated with a diffuse indifferenciated lymphoma. report of case. In: Congreso Panamericano de Neurologia 8. Montevideo, 1991, p 134. 
16. Brentani MM, Marchiori PE, Martins VR. Glucocorticoid receptors of mononuclear leukocytes from myasthenia gravis patients. Acta Neurol Scand 1985, 72: 788-792.

17. Eaton LM, Clagett OT. Present status of thymectomy in the treatment of myasthenia gravis. Am J Med 1955, 19: 703-717.

18. Glaser GH, Merritt HH. Effects of corticotropin (ACTH) and cortisone on disorders of the nervous system. JAMA 1952, 148: 898-904.

18a. Haddad MS, Baeta AM, Tinone G, Assis JL, Marchiori PE, Scaff M. Development of myasthenia gravis (MG) after splenectomy. In J Neuroimmunol 1991, Suppl 1 (Internat Congr of Neuroimmunol 3. Jerusalem 1991), p 196.

18b. Haddad MS, Assis JL, Marchiori PE, Scaff M. Myasthenia gravis and uveitis. Report of two cases. In Congreso Panamericano de Neurologia 8. Montevideo, 1991, p 133.

19. Kane CA. The effect of certain endocrine glands on myasthenia gravis. Am J Med 1955, 19:729-733.

20. Lazzari AA, Marchiori PE, Oliveira RM, Reis M, Scaff M, Assis JL, Cossermelli W. High prevalence of antibodies against collagen in patients with myasthenia gravis: preliminary note. Neurobiologia (Recife) 1984, 47: 63-64.

21. Lusvarghi E, Brotto M. Testes eletrofisiológicos: eletromiografia no diagnóstico da miastenia grave. In: Assis JL. Miastenia Grave. São Paulo: Sarvier, 1990, p 53.

22. Marchiori PE, Scaff M, Mello EP, Trindade VS, Assis JL. Plasmaférese sem imunossupressão concomitante em miastenia grave: registro de caso. Rev Hosp Clín Fac Med S Paulo 1981, 36: 278-281.

23. Marchiori PE, Oliveira RM, Scaff M, Reis M, Cossermelli W, Assis JL. anti-acetylcholine receptor antibodies in patients with myasthenia gravis: preliminary note. Neurobiologia (Recife) 1984, 47: 61-62.

24. Marchiori PE. Anticorpo anti-receptor de acetilcolina em miastenia grave. Tese. Fac Med Univ São Paulo. São Paulo, 1985.

25. Marchiori PE, Oliveira RM, Trindade VS, Scaff M, Assis JL, Cossermelli W. Circulating immune complexes in myasthenia gravis. Rev Hosp Clín Fac Med S Paulo 1985, 40: 13-14.

26. Marchiori PE. Identificação e significado de elementos imunológicos e morfológicos na miastenia grave: valor diagnóstico para o timoma. Tese. Fac Med Univ São Paulo. São Paulo, 1987.

27. Marchiori PE, Scaff M, Assis JL. Failure of cyclosporin-A in myasthenia gravis. Arq Neuropsiquiatr 1989, 47: 91-93.

28. Marchiori PE, Roela RA, Koike MAA, Frederico HH, Brentani MM. Phenotypic analyses of thymus lymphocytes from patients with myasthenia gravis. In: International Congress of Immunology 8. Budapest, 1992, p 44.

29. Marchiori PE, Roela RA, Koike MAA, Frederico HH, Haddad M, Brentani MM. Integrin receptors analyses of thymic lymphocytes from patients with myasthenia gravis. In: International Congress of Immunology 8. Budapest, 1992, p 45.

30. Marchiori PE. Imunogenética. In: Assis JL. Miastenia grave. São Paulo: Sarvier, 1990, p 177.

30a. Marchiori PE, Assis JL, Scaff M. Use of cytolytic drugs in myasthenia gravis. In: J Neuroimmunol 1991, Suppl 1 (International Congress of Neuroimmunol 3,. Jerusalem, 1991) p 197.

30b. Marchiori PE, Zambon AA, Assis JL, Scaff M. Myasthenia gravis: clinical and histopathological correlations in thymectomized patients. In J Neuroimmunol 1991 Suppl 1 (Internat Congr of Neuroimmunol 3. Jerusalem, 1991) p 197.

30c. Marchiori PE, Scaff M, Assis JL, Saraiva PAP. Evaluation of the larynx muscle dysfunction in myasthenia gravis: an aid for diagnosis of MG using the respiratory function analysis. In Can J Neurol Sci, 1993, 20, Suppl 4. (World Congr Neurol 15, Vancouver 1993) p S99.

30d. Marchiori PE, Scaff M, Assis JL, Brentani MM, Martino VR. Neuroendocrinological evaluation on myasthenia gravis. In: Can J Neurol Sci 1993, 20, Suppl 4 (World Congr Neurol 15, Vancouver 1993) p S135. 30e. Marchiori PE, Scaff M, Assis JL, Tuma MF. The clinical and electrophysiological correlation of the blocking effect of antiacetylcholine receptor antibody in a vivo neuromuscular preparation of rats. In Can J Neurol Sci 1993, 20, Suppl 4 (World Congr Neurol 15, Vancouver 1993) p S99.

31. Maria DA, Marchiori PE, Gauditano G, Pozzi DHB, Assis JL. Antibody-dependent citotoxicity (ADCC) patients with myasthenia gravis. In: Congreso Panamericano de Neurologia 8. Montevideo, 1991, p 127.

32. Marshal AEH, White RG. Experimental thymic lesions resembling those of myasthenia gravis. Lancet 1961, 1: 1030-1031.

33. Mendes N, Koperstych S, Saraiva S, Assis JL. Imunidade celular na miastenia grave. Rev Hosp Clín Fac Med S Paulo 1978, 33:272-276.

34. Millikan CH, Eaton LM. Clinical evaluation of ACTH in myasthenia gravis. Neurology 1951,1:145-152. 35. Nastuk WL, Strauss AJL, Osserman KE. Search of a neuromuscular blocking agent in the blood of patients with myasthenia gravis. Am J Med 1959, 26: 394-409. 
36. Nastuk WL, Plescia OJ, Osserman KE. Changes in serum complement activity in patients with myasthenia gravis. Proc Soc Exp Biol Med 1960, 105: 177-184.

37. Oliveira RM, Marchiori PE, Reis M, Zambon AA, Cossermelli W, Scaff M, Assis JL. Antibodies against an extractable muscle antigen in patients with myasthenia gravis: preliminary note. Neurobiologia (Recife) 1984, 47: 65-66.

38. Reis M, Quevedo MEZ, Brentani MM, Oliveira RM, Assis JL, Scaff M, Marchiori PE. Anti-laminin antibody in myasthenia gravis. In International Symposium of Immunology 7. Berlin, 1989.

39. Reis M, Oliveira RM, Quevedo ME, Scaff M, Marchiori PE. Acetylcholine receptor antibody in myasthenia gravis: the scatchard plot evaluation. In: Congreso Panamericano de Neurologia 8. Montevideo, 1991, p 132. 40. Saraiva S, Assis Jl, Camargo EM, Marlet JM. Myasthenia gravis: aspects of the clinical immunological correlation. Rev Hosp Clin Fac Med S Paulo 1971, 26: 111-114.

41. Saraiva PAP, Assis Jl, Marchiori PE. Evaluation of the respiratory function in myasthenia gravis: an innovative diagnostic tool. In: Journées Internacionales de Pathologie Neuromusculaire 11. Marseille, 1992.

42. Saraiva PAP, Assis JL, Marchiori PE. Evaluation of the respiratory function in myasthenia gravis: an innovative diagnostic tool. Trabalho para publicação.

43. Savoy CV. Miastenia grave. Tese. Fac Med Univ São Paulo. São Paulo, 1945.

44. Schlesinger NS. Present status of therapy in myasthenia gravis. JAMA 1952, 148: 508-513.

45. Simpson JA. Evaluation of thymectomy in myasthenia gravis. Brain 1958, 81: 112-144.

46. Simpson JA. Myasthenia gravis: a new hypothesis. Scot Med J 1960, 5: 419-456.

47. Strauss AJL, Seegal BC, HSU KC, Burkholder PM, Nastuk WL, Osserman KE. Immunofluorescence demonstration of a muscule-binding complement-fixing serum globulin fraction in myasthenia gravis. Proc Soc Exp Biol 1960, 105: 184-191.

48. Stump XMGRG. Tomografia axial computadorizada do mediastino anterior. In Assis JL. Miastenia grave. São Paulo: Sarvier, 1990, p 47.

49. Tinone G, Haddad MS, Baêta AM, Marchiori PE, Assis JL, Scaff M. Myasthenia gravis and psoriasis: a case report. In: J Neuroimmunol 1991, Suppl 1. (Internat Congr Neuroimmunol 3, Jerusalem, 1991) p 196.

50. Tuma MFF. Miastenia grave induzida em animais por gamaglobulina de pacientes miastênicos: estudo clínico e eletrofisiologia em preparação neuromuscular. Tese. Fac Med Univ São Paulo. São Paulo, 1990.

50a. Tuma MFF, Marchiori PE, Iaria CT. Experimental autoimmune myasthenia gravis by immunoglobulin of myasthenic patients: clinical and mechanical evaluation in a vivo neuromuscular system. Congreso Panamericano de Neurologia 8. Montevideo, 1991, p 128.

51. Vampré E. Moléstia de Erb-Goldfram. Comunicação feita na Sociedade de Medicina e Cirurgia de São Paulo em 08/09/1915. In Livro de Atas 8, p 2.

52. Viana VST, Bueno C, Oliveira RM, Marchiori PE, Cossermelli W, Scaff M, Assis JL. Enzyme-linked immunosorbent assay for detection of antibodies in myasthenia gravis. First IUIS/Conference on Clinical Immunology (July, 1986). In: International Congress of Immunology 6. Toronto, 1986.

53. Viana VST, Bueno C, Oliveira RM, Marchiori PE, Cossermelli W, Scaff M, Assis JL. Enzyme-linked immunosorbent assay for detection of antibodies to extractable muscle antigens in myasthenia gravis. Acta Neurol Scand 1986, 75: 599-601.

54. Weltman E, Marchiori PE, Assis J, Zambon AA, Tinone G. Failure of the total body irradiation in polymyositis and myasthenia gravis: report of 4 cases. In Congreso Panamericano de Neurologia 8. Montevideo, 1991, p 19. 55. Wendel SN. Métodos que removem anticorpos e células imunoagressivas: tratamento das crises miastênica e colinérgica. In Assis JL. Miastenia grave. São Paulo: Sarvier, 1990, p 253.

56. Zambon AA. Timectomia na miastenia grave: avaliação de 150 pacientes em estudo histopatologico do timo. Tese. Fac Med Univ São Paulo. São Paulo 1991.

56a. Zambon AA, Marchiori PE, Assis JL, Schultz R, Scaff M. Evaluation of demographic factors in MG: clinical and histopathological changes of the prednisone previous administration. In Congreso Panamericano de Neurologia 8. Montevideo, 1991, p 128. 